\title{
Índice de estado trófico, baseado no fósforo, na bacia hidrográfica Paraguai-Diamantino em Mato Grosso, Brasil
}

A qualidade da água pode ser alterada naturalmente em função do contato com o substrato rochoso e edáfico, no percurso hidrológico, podendo adquirir características destes substratos em maior ou menor proporção. Porém, a concentração demográfica urbana, o avanço tecnológico das práticas agropecuárias e industriais, dentre outras ações antrópicas, também influenciam a qualidade das águas, geralmente de modo negativo e impactante. Independente da origem da alteração de qualidade, esta deve ser monitorada para o conhecimento científico e gestão geoambiental. Neste contexto, realizaram-se amostragens em nove (9) pontos na bacia Paraguai-Diamantino, com o objetivo de analisar a concentração de fósforo total e o seu efeito na eutrofização das águas. Para isso, coletaram-se amostras de água em quatro períodos, conforme as estações de chuva, seca e transições e utilizou-se do Índice de Estado Trófico (IET), conforme recomendação do Programa Nacional de Avaliação da Qualidade das Águas (PNQA). Observou-se alteração do IET entre os cursos d'água, entre os períodos de coleta e entre pontos do mesmo curso d'água, neste caso o rio Paraguai. O IET variou entre as ponderações $0,50,1,00,2,00$ e 3,00. Concluiu-se que há variação de qualidade da água em relação ao IET apontando para diversidade de contaminação por fósforo, em relação à sua concentração. O IET se enquadrou nas classes superiores de qualidade não encontrando concentração de fósforo que indicasse eutrofização aguda.

Palavras-chave: Eutrofização; Águas Superficiais; Gestão de Recursos Hídricos.

\section{Trophic state index phosphorus-based in the Paraguay-Diamantino basin in the Mato Grosso, Brazil}

\begin{abstract}
The quality of the water can be altered naturally due to the contact with the rocky and edaphic substrate in the hydrological course, which can acquire characteristics of these substrates to a greater or lesser extent. However, urban demographic concentration, the technological advance of agricultural and industrial practices, among other anthropogenic actions, also influence water quality, generally in a negative and shocking way. Regardless of the origin of the quality change, it should be monitored for scientific knowledge and geo-environmental management. In this context, sampling was carried out in the nine water courses in the Paraguay-Diamantino basin, aiming to analyze the total phosphorus concentration and its effect on water eutrophication. For this, water samples were collected in four periods, according to rainfall, drought and transitional seasons, and determined from the Trophic State Index (EITP), as recommended by the National Wate Quality Assessment Program (PNQA). There was a change in the EIT between the watercourses, between the collection periods and between points in the same watercourse, in this case the Paraguay River. The EIT varied between the weights $0.50,1.00,2.00$ and 3.00 . It was concluded that there is variation of water quality in relation to the EITP, pointing to diversity of phosphorus contamination, in relation to its concentration. The EITP fell within the highest quality classes and no concentration of phosphorus indicating acute eutrophication was found.
\end{abstract}

Keywords: Eutrophication; Surface Water; Management of Water Resources.

Topic: Desenvolvimento, Sustentabilidade e Meio Ambiente

Reviewed anonymously in the process of blind peer.
Received: 11/12/2019

Approved: 11/01/2020

Tadeu Miranda de Queiroz (i)

Universidade do Estado de Mato Grosso, Brasil

http://lattes.cnpq.br/2582121765769124

http://orcid.org/0000-0002-1959-7658

tdmqueiroz@unemat.br

Adriana Ferreira Lima

Universidade do Estado de Mato Grosso, Brasil

http://lattes.cnpq.br/8586436222819846

http://orcid.org/0000-0002-8376-326X

lima.adrianaferreira87@gmail.com

Edinéia Aparecida dos Santos Galvanin (iD)

Universidade Estadual Paulista, Brasil

http://lattes.cnpq.br/5041881204275768

http://orcid.org/0000-0002-6678-9599

galvanin@gmail.com

Referencing this:

QUEIROZ, T. M.; LIMA, A. F.; GALVANIN, E. A. S.. Índice de estado trófico, baseado no fósforo, na bacia hidrográfica ParaguaiDiamantino em Mato Grosso, Brasil. Revista Ibero Americana de Ciências Ambientais, v.11, n.1, p.300-308, 2020. DOI: http://doi.org/10.6008/CBPC2179-6858.2020.001.0027 


\section{INTRODUÇÃO}

A água, solvente universal e composto fundamental para a existência da vida, desperta interesse da comunidade científica desde os primórdios da civilização. Na atualidade o maior desafio é a convivência com a escassez, seja ela motivada pela oferta reduzida ou pela má qualidade, que em muitos casos inviabiliza o uso. O Brasil enfrenta uma situação de déficit hídrico na região semiárida desde o período colonial e mais recentemente tem enfrentado crises de seca como a que ocorreu no Acre em 2013, São Paulo (sistema Cantareira e adjacentes) em 2015, Tangará da Serra/MT em 2016 e Brasília/DF que enfrentou racionamento e risco de desabastecimento durante a maior parte do ano de 2017, conforme o noticiário nacional.

A população, de modo geral, entende a escassez hídrica quando falta água na torneira ou quando há surto de doenças de veiculação hídrica, as quais acometem principalmente às crianças, conduzindo países como o Brasil (5a maior economia do mundo) a índices alarmantes de mortalidade infantil. Neste cenário atuam as agências de regulação governamentais, empresas públicas de pesquisa, e com forte contribuição, as universidades públicas, que através de seus programas de pós-graduação fomentam a pesquisa científica livre, sendo grande parte dela com enfoque regional com o olhar voltado para problemas locais que funcionam como lente de aumento para agravantes ambientais.

A principal preocupação em relação ao abastecimento público de água está relacionada à sua potabilidade e ao fornecimento seguro e ininterrupto. Embora exista total pertinência na preocupação com a potabilidade da água que chega à torneira é fundamental também o conhecimento da qualidade da água na fonte, mas não somente da qualidade no ponto de captação, mas a qualidade distribuída no tempo e no espaço. A observação espaço-temporal da qualidade da água numa bacia hidrográfica permite inferir sobre as causas de poluição e contaminação além de permitir o planejamento e estimativa de cenários futuros.

A qualidade da água numa bacia hidrográfica pode ser medida pela determinação da concentração de sais, metais, moléculas tóxicas, hormônios, organismos patogênicos, entre outros. No Brasil os padrões de qualidade das águas superficiais há a Resolução № 357 de 2005 do Conselho Nacional de Meio Ambiente (CONAMA), que classifica os corpos d'água em classes de uso, além de dar outras providências para o lançamento de efluentes.

Embora as portarias e resoluções que definem padrões de potabilidade sejam bastante úteis, a literatura científica tem apontando para a proposição de índices que visam agregar um conjunto de variáveis para expressar a qualidade por um único número. Isso com o objetivo de simplificar a forma de expressar a qualidade da água de um manancial e facilitar a comunicação com a sociedade, porém sem perder de vista as variáveis e parâmetros normatizados.

Neste sentido, há diversos índices que buscam classificar a qualidade da água para situações específicas. O Programa Nacional de Avaliação da Qualidade das Águas (PNAQ) da Agência Nacional de Águas (ANA), vinculada à Secretaria de Recursos Hídricos do Ministério do Meio Ambiente, sugere 7 índices diferentes. Um deles é o Índice de Estado Trófico (IET), o qual foi proposto em 1977 por Robert E. Carlson, pesquisador do Limnological Research Center da University of Minnesota, e ainda utilizado na atualidade 
como demonstram os trabalhos de Prasad et al. (2012) e Silvino et al. (2015).

O IET de Carlson foi desenvolvido para lagos e engloba medições de transparência pelo disco de Secchi, concentração de Fósforo e Clorofila, e classifica o Estado Trófico em 11 faixas que vão de 0 a 100, variando de 10 em 10 (CARLSON, 1977). Durante muito tempo essa metodologia foi utilizada também para estimativa da eutrofização em rios, mas sugestões de adaptação surgiram, sendo a de Lamparelli (2004) a mais recente e mais citada e aceita na literatura específica atual, para as condições do Brasil.

Lamparelli (2004) observou que em ambientes lóticos são encontradas maiores concentrações de Fósforo e menores concentrações de Clorofila- $a$ do que em ambientes lênticos. Por isso, o autor propôs equações distintas para estimativa do IET em ambientes lênticos e lóticos. Corrobora a isso o fato de que a concentração de Fósforo deve ser entendida como o potencial de eutrofização, ou seja, a causa e as concentrações de Clorofila- $a$ e Transparência são medidas de efeito da eutrofização (BAUMGARTEN et al., 2015).

Em rios com corredeiras e cascatas, a alta velocidade da água dificulta a determinação da Clorofilaa, motivo pelo qual alguns autores estimam o IET com base apenas na concentração de Fósforo total, como fizeram Gomes et al. (2010), Farage et al. (2010), Ferreira et al. (2014), Silva et al. (2014), Abreu et al. (2017), entre outros. Farage et al. (2010) também destacam a dificuldade de determinação da transparência em rios de regime lótico devido a turbidez provocada pela presença de material em suspensão, típico desses ambientes. Neste caso, utilizando apenas a concentração de Fósforo para estimativa do estado trófico, Farage et al. (2010), Ferreira et al. (2014) e Silva et al. (2014) denominaram esse índice de IET baseado no Fósforo (IET $\mathrm{P})$. Neste contexto e com base na literatura específica, o presente trabalho teve por objetivo avaliar o IETP para a Bacia Hidrográfica Paraguai/Diamantino (BHPD) em 4 períodos, estratificados conforme o regime de chuvas da região.

\section{MATERIAIS E MÉTODOS}

A BHPD, localiza-se entre as serras Tira Sentido, na Província Serrana, e Tapirapuã, no Planalto dos Parecis. Possui cerca de $695,00 \mathrm{~km}^{2}$ e está situada no centro norte do estado de Mato Grosso, entre as

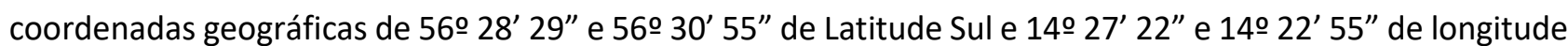
Oeste. É formada por 8 sub-bacias em cujos principais tributários estão localizados os pontos amostrais: $1 \mathrm{e}$ 2 no Rio Paraguai, 3 no Rio Diamantino, 4 no córrego Frei Manoel, 5 no córrego Buriti, 6 no córrego Mato Seco, 7 no córrego Macaco, 8 no córrego Amolar e 9 no córrego Melgueira (Figura 1).

De acordo com Casarin (2007) o relevo desta bacia é composto pela porção plana no planalto dos Parecis, onde estão localizadas, as nascentes do rio Paraguai e tributários como Amolar, Macaco e Melgueira, favoráveis a atividades agrícolas mecanizadas e pastagens, e a Depressão do rio Paraguai, marcada por extensas áreas de extrativismo mineral, que se estende até as planícies pantaneiras.

O clima regional é Aw, quente e úmido, com estação seca no outono/inverno e a estação chuvosa na primavera/verão, conforme a classificação climática proposta por Köppen. Esse tipo climático está presente na região Norte, Médio-Norte, Centro-Sul do Estado de Mato Grosso (SOUZA et al., 2013). As amostras de 
água foram coletadas (em frasco de polietileno esterilizados) a $30 \mathrm{~cm}$ de profundidade, contra a corrente e evitando as margens e zonas lênticas. Após coleta, as mesmas foram preservadas em recipiente refrigerado com gelo até a entrega no laboratório para análise, em no máximo 24 horas. Aos recipientes de coleta se adicionaram 10 gotas de ácido sulfúrico 50\% para neutralizar o efeito dos microrganismos na degradação do fósforo. Os pontos amostrados estão descritos no Quadro 1, com referência ao nome do curso d'água e coordenadas geográficas.

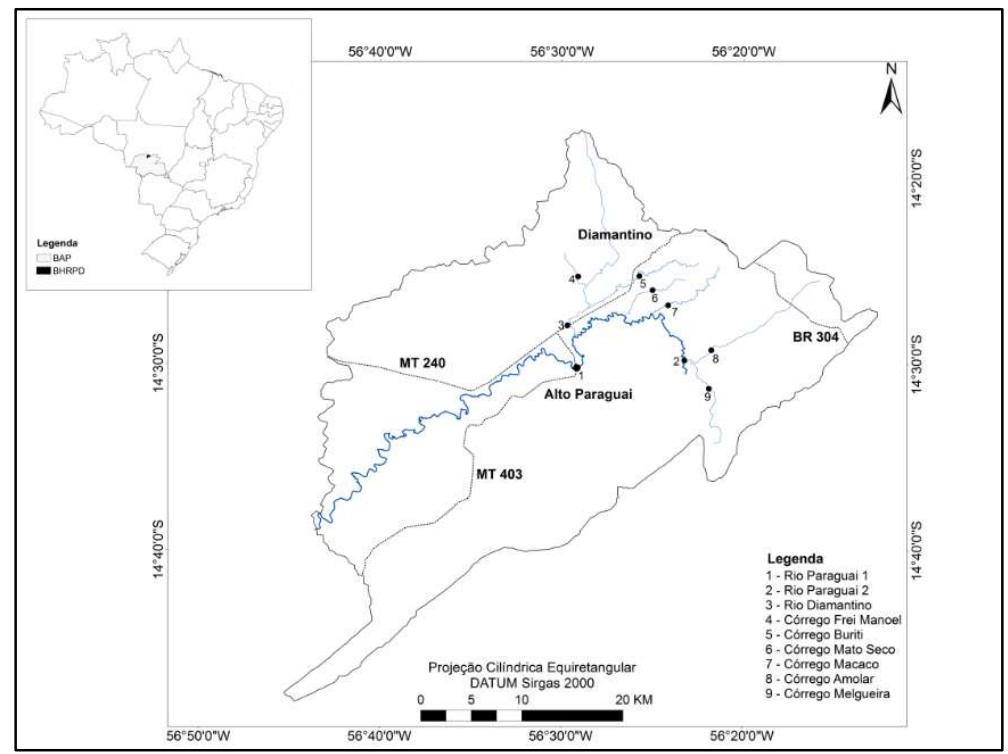

Figura1. Mapa de localização da BHPD, rede de drenagem principal e pontos de monitoramento.

Quadro 1: Nome dos cursos d'água e coordenadas geográficas dos pontos de coleta.

\begin{tabular}{|l|l|l|}
\hline Ponto & Nome & Coordenadas (Latitude; Longitude) \\
\hline P1 & Rio Paraguai 1 & $14029,782^{\prime} \mathrm{S} ; 56003,350^{\prime} \mathrm{W}$ \\
\hline P2 & Rio Paraguai 2 & $14030,212^{\prime} \mathrm{S} ; 56029,091^{\prime} \mathrm{W}$ \\
\hline P3 & Rio Diamantino & $15003,715^{\prime} \mathrm{S} ; 57010,698^{\prime} \mathrm{W}$ \\
\hline P4 & Córrego Frei Manoel & $14025,326^{\prime} \mathrm{S} ; 56029,104^{\prime} \mathrm{W}$ \\
\hline P5 & Córrego Buriti & $14025,276^{\prime} \mathrm{S} ; 56025,178^{\prime} \mathrm{W}$ \\
\hline P6 & Córrego Mato Seco & $14025,404^{\prime} \mathrm{S} ; 56005,380^{\prime} \mathrm{W}$ \\
\hline P7 & Córrego Macaco & $14025,596^{\prime} \mathrm{S} ; 56005,800^{\prime} \mathrm{W}$ \\
\hline P8 & Córrego Amolar & $14029,260^{\prime} \mathrm{S} ; 56001,745^{\prime} \mathrm{W}$ \\
\hline P9 & Córrego Melgueira & $14031,312^{\prime} \mathrm{S} ; 56021,877^{\prime} \mathrm{W}$ \\
\hline
\end{tabular}

Alguns dos córregos recebem localmente a designação de ribeirão, mas, neste trabalho considerouse um sinônimo do outro e padronizou-se a nomenclatura para córrego com o objetivo de simplificar a descrição. Foram feitas coletas em 4 períodos distintos (Quadro 2), conforme estratificação proposta por Martins et al. (2011), em função do regime pluviométrico regional. Esta estratificação do regime hídrico, seja em função da chuva ou vazão, é conveniente, uma vez que tenta considerar o efeito do carreamento de detritos e nutrientes da superfície do solo para os cursos d'água, além de considerar o aumento da vazão na diluição da carga poluidora. Estratificação semelhante foi feita por Alves et al. (2012) quando avaliaram o IET no rio Arari na Ilha de Marajó considerando dois regimes hidrológicos distintos: descarga máxima (abril e maio) e descara mínima (setembro e outubro). Os períodos considerados por Alves et al. (2012) coincidem com os períodos de transição de Martins et al. (2011), o que faz sentido se considerar que o primeiro realizou estudo na região Amazônica e o segundo numa área considerada de transição entre Cerrado e Amazônia. 
Quadro 2: Períodos, intervalo, Índice de Precipitação (IP) e data de coleta de água

\begin{tabular}{|l|l|l|l|}
\hline Período & Intervalo & IP (\%) & Data da Coleta \\
\hline Transição 2 & Setembro - Outubro & 12,34 & $05 / 10 / 2015$ \\
\hline Chuvoso & Novembro - Março & 74,40 & $29 / 02 / 2016$ \\
\hline Transição 1 & Abril - Maio & 10,74 & $25 / 04 / 2016$ \\
\hline Seco & Junho - Agosto & 2,58 & $05 / 06 / 2016$ \\
\hline
\end{tabular}

A concentração de fósforo total em $\mathrm{mg} \cdot \mathrm{L}^{-1}$ foi determinada em laboratório certificado e credenciado seguindo a metodologia recomendada pela American Public Health Association (APHA et al., 1996), conforme citação indicada no relatório de análises. O IET para o fósforo foi calculado pela Equação 1, conforme

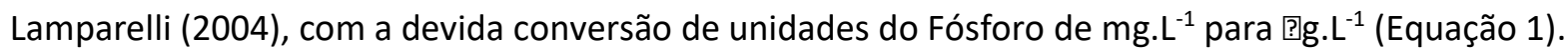

$$
\mathrm{IET}_{\mathrm{P}}=10\left[6-\frac{0,42-0,36 \ln (\mathrm{PT})}{\ln (2)}\right] \quad \text { Eq. } 1
$$

Onde: IETp é o Índice de Estado Trófico baseado no fósforo (adimensional); PT é a concentração de Fósforo Total (?]g.L-

$\left.{ }^{1}\right)$ e In é o Logaritmo Neperiano.

A categorização e ponderação do estado trófico foi feita com base nas classes estipuladas por Lamparelli (2004), conforme Quadro 3.

Quadro 3: Categorização e Classes adotadas no enquadramento do IET

\begin{tabular}{|l|l|l|}
\hline $\mathrm{IET}$ & Categorização & Classes \\
\hline $\mathrm{IET}<47$ & Ultraoligotrófico & 0,5 \\
\hline $47<\mathrm{IET} \leq 52$ & Oligotrófico & 1 \\
\hline $52<\mathrm{IET} \leq 59$ & Mesotrófico & 2 \\
\hline $59<\mathrm{IET} \leq 63$ & Eutrófico & 3 \\
\hline $63<\mathrm{IET} \leq 67$ & Supereutrófico & 4 \\
\hline $\mathrm{IET}>67$ & Hipereutrófico & 5 \\
\hline
\end{tabular}

Para estudo da eutrofização é suficiente conhecer o valor do IET e sua relativa categoria, mas como o IET também é componente de outros índices, o mesmo foi associado às classes para cada estado trófico.

\section{RESULTADOS E DISCUSSÃO}

As concentrações de fósforo nas águas naturais oscilam entre 0,005 e 0,02 mg. L $^{-1}$ conforme citação de Chapman (1992). Quaisquer ocorrências de concentração superior desse nutriente em cursos d'água indicam a probabilidade de existência de contribuição antrópica para o enriquecimento das águas, seja por despejo de efluentes, carreamento de material orgânico e transporte de nutrientes das áreas cultivadas. Na Tabela 1 apresenta-se o resultado das análises de Fósforo Total para cada ponto e período.

Tabela 1: Concentração de Fósforo Total $\left(\mathrm{mg}^{\mathrm{L}} \mathrm{L}^{-1}\right)$ de cada ponto nos 4 períodos.

\begin{tabular}{|c|c|c|c|c|c|c|c|c|c|c|}
\hline \multirow[t]{2}{*}{ Período } & \multirow[t]{2}{*}{ Data } & \multicolumn{9}{|c|}{ Pontos de Coleta } \\
\hline & & P1 & $\mathrm{P} 2$ & P3 & P4 & P5 & P6 & P7 & P8 & P9 \\
\hline Transição 1 & $05 / 10 / 2015$ & 0,06 & 0,04 & 0,04 & 0,05 & 0,15 & NC & 0,05 & 0,03 & 0,05 \\
\hline Chuvoso & $29 / 02 / 2016$ & 0,08 & 0,10 & 0,12 & 0,02 & 0,09 & 0,06 & 0,04 & 0,13 & 0,01 \\
\hline Transição 2 & $25 / 04 / 2016$ & 0,05 & 0,02 & 0,01 & 0,01 & 0,01 & 0,11 & 0,04 & 0,07 & 0,01 \\
\hline Seco & $05 / 06 / 2016$ & 0,02 & 0,01 & 0,01 & 0,01 & 0,02 & 0,05 & 0,02 & 0,05 & 0,01 \\
\hline
\end{tabular}

NC = não coletado (vazão zero).

Observa-se pelos dados da Tabela 1 que apenas 4 pontos (P3, P5, P6 e P8) apresentaram valor de Fósforo Total (PT) superior ao Valor Máximo Permitido (VMP) da Resolução 357/2005 do CONAMA que é de 0,10 mg. $\mathrm{L}^{-1}$ para água doce de rios de Classe 1 , considerando o ambiente lótico. Cabe destaque para o fato 
de que o ponto P5 apresentou maior concentração de PT no período de Transição 2 (seca - chuva), os pontos P3 e P8 teve maior concentração no período Chuvoso e no ponto P6 a maior concentração foi no período de Transição1 (chuva - seca). O período Seco revelou menores concentrações de PT em todos os pontos, com concentração sempre inferior a 0,05 mg. $\mathrm{L}^{-1}$, que é metade do VMP. Os demais pontos apresentam valores até 10 vezes inferior ao máximo permitido, indicando que, isoladamente, o PT não se apresenta em concentração de alerta.

Gomes et al. (2010), em estudo realizado no rio Catolé na Bahia, também verificaram maior concentração de Fósforo no período chuvoso. Os autores atribuíram essa concentração devido ao carreamento de fósforo para o rio pelo deflúvio superficial. Já Farage et al. (2010) encontraram maior concentração de Fósforo em pontos do rio Pomba onde havia lançamento de grande carga de efluentes domésticos e industriais.

Alves et al. (2012) encontraram no rio Arari concentração (mediana) entre 0,13 e 0,23 mg.t-1 de PT, valores estes típicos de ambiente com forte pressão antrópica, porém devido à baixa descarga de esgoto doméstico no referido rio, os autores sugeriram que o aporte de fósforo tem origem nos campos naturais. Esse resultado, quando comparado com a presente pesquisa, faz crer que na BHPD o aporte de PT pode ser tanto de origem do esgoto doméstico, quanto da agricultura, uma vez que o Fósforo é um macro nutriente largamente utilizado em fertilizantes artificiais e a região é circundada pela agricultura moderna, traduzida como agronegócio. Farage et al. (2010) e Silvino et al. (2015) também relataram o escoamento superficial no período chuvoso como responsável pelo carreamento de fósforo do solo para os corpos de rios.

Tabela 2: Resultado individualizado por ponto de coleta e período representado pelo valor do IETp e (Categoria)

\begin{tabular}{|c|c|c|c|c|c|}
\hline \multirow{2}{*}{ Pontos de Coleta } & \multicolumn{4}{|l|}{ Períodos } & \multirow{2}{*}{ Média } \\
\hline & Transição 2 & Chuvoso & Transição 1 & Seco & \\
\hline P1 - R. Paraguai 1 & $55,21(\mathrm{M})$ & $56,70(\mathrm{M})$ & $54,26(\mathrm{M})$ & $49,50(0)$ & $53,92(\mathrm{M})$ \\
\hline P2 - R. Paraguai 2 & $53,10(\mathrm{M})$ & $57,49(\mathrm{M})$ & $49,50(0)$ & $45,90(U)$ & $51,59(0)$ \\
\hline P3 - R. Diamantino & $53,10(\mathrm{M})$ & $58,81(\mathrm{M})$ & $45,90(U)$ & $45,90(U)$ & $50,93(0)$ \\
\hline P4 - C. Frei Manoel & $54,26(\mathrm{M})$ & $49,50(0)$ & $45,90(U)$ & $45,90(U)$ & $48,89(0)$ \\
\hline P5 - C. Buriti & $59,96(\mathrm{M})$ & $57,31(\mathrm{M})$ & $45,90(U)$ & $49,50(0)$ & $53,17(\mathrm{M})$ \\
\hline P6 - C. Mato Seco & $\mathrm{NC}$ & $55,21(\mathrm{M})$ & $58,35(\mathrm{M})$ & $54,26(\mathrm{M})$ & $55,94(\mathrm{M})$ \\
\hline P7 - C. Macaco & $54,26(\mathrm{M})$ & $53,10(\mathrm{M})$ & $53,10(\mathrm{M})$ & $49,50(0)$ & $52,49(0)$ \\
\hline P8-C. Amolar & $51,61(0)$ & $59,22(E)$ & $56,01(\mathrm{M})$ & $54,26(\mathrm{M})$ & $55,27(0)$ \\
\hline P9-C. Melgueira & $54,26(\mathrm{M})$ & $45,90(U)$ & $45,90(\mathrm{U})$ & $45,90(U)$ & $47,99(0)$ \\
\hline Média & 54,47 (M) & $54,84(\mathrm{M})$ & $50,54(0)$ & $48,96(0)$ & $52,14(\mathrm{M})$ \\
\hline
\end{tabular}

$\mathrm{U}=$ Ultraoligotrófico; $\mathrm{O}=$ Oligrotrófico; $\mathrm{M}=$ Mesotrófico; $\mathrm{E}$ = Eutrófico. NC = Não coletado.

Alemayehu et al. (2016), estudando o Índice de Estado Trófico no lago Kaw em Oklahoma/USA, também sugeriram que as atividades antrópicas, entre elas a agricultura, a indústria e a deposição de esgotos, são fatores que podem potencializar a eutrofização, embora o crescimento de algas também possa ser fruto da deposição de sedimentos no lago ao longo do tempo. Na BHPD deve se desconsiderar as causas naturais de eutrofização motivada pela deposição de sedimentos, uma vez que os corpos d'água não apresentam tais características, portanto as causas do enriquecimento das águas por fósforo devem estar associadas aos despejos de efluentes urbanos e agroindustriais e também o carreamento desse nutriente pelo escoamento superficial das águas das chuvas. Na Tabela 2 apresenta-se o resultado do IETP para cada ponto e cada período avaliado e sua respectiva categoria entre parênteses. 
O IET nos pontos e períodos avaliados oscilou entre 45,90 e 59,96, faixa correspondente às categorias Ultraoligotrófico, Oligotrófico, Mesotrófico e Eutrófico. O valor médio para todo curso d'água considerando os 4 períodos foi de 52,14 o que converge para a categoria Mesotrófica. Em estudo nos rios Anil e Bacanga, em São Luiz/MA, Silva et al. (2014) encontraram estado trófico variando de Mesotrófico a Hipereutrófico. Os autores atribuíram esse resultado às atividades agropecuárias e povoamentos no entorno do curso d'água, caso semelhante às condições da BHPD.

Corpos d'água Ultraoligotróficos são limpos, com produtividade e concentrações de nutrientes muito baixas que não representam prejuízos aos usos da água. Os Oligotróficos são corpos d'água também limpos, com baixa produtividade e sem interferências indesejáveis, decorrentes da presença de nutrientes. Já os Mesotróficos são aqueles que apresentam produtividade intermediária, com possíveis implicações sobre a qualidade da água, porém em níveis aceitáveis, na maioria dos casos. Corpos d'água Eutróficos, apresentam alta produtividade em relação às condições naturais, com redução da transparência, em geral afetados por atividades antrópicas, nos quais ocorrem alterações indesejáveis na qualidade da água decorrentes do aumento da concentração de nutrientes e interferências nos seus múltiplos usos (BRASIL, 2017).

Neste estudo verificou-se situação de Eutrofia apenas no Córrego Amolar no período chuvoso. Resultado compatível com as concentrações de fósforo e com as características da bacia, composta nesta região, pela porção plana no planalto dos Parecis, onde estão localizados, as nascentes do rio Paraguai e tributários como Amolar, Macaco e Melgueira, favoráveis a atividades agrícolas mecanizadas e pastagens como reportado por Casarin (2007).

Observando isoladamente o rio Paraguai nos dois pontos, sendo o P2 próximo à nascente principal e P1 o ponto mais distante da nascente, observa-se que ambos mantiveram a mesma categoria trófica (M) nos períodos Transição 2 e chuvoso. No período Transição 1 o ponto P1 manteve a categoria trófica enquanto P2 melhorou passando de Mesotrófico para Oligotrófico e no período Seco ambos melhoram o estado trófico. Esse resultado reflete o efeito diluitório da descarga do rio Diamantino no ponto P1, uma vez que neste período sua água foi categorizada como Ultraoligotrófica. Já o resultado inferior no ponto P1 reflete a descarga dos córregos Amolar e Melgueira, uma vez que o Amolar foi o único que se apresentou como Eutrófico.

A análise dos pontos P1 e P2 no rio Paraguai revela melhoria da qualidade da água entre P2 e P1, ou seja, entre a proximidade da nascente principal e a foz. A razão para essa melhoria pode ser o efeito diluitório da carga poluidora e também da autodepuração do próprio rio. Lopes et al. (2010), explicam que as características morfométricas de uma bacia como a formação de corredeiras e quedas d'água favorecem a autodepuração da carga poluidora de um rio. Corredeiras e cachoeiras são presentes na bacia Paraguai/Diamantino, o que pode estar contribuindo para melhoria do estado trófico ao longo do percurso do rio.

Ainda pelos dados da Tabela 2, observando os valores médios de IETp em cada período e suas respectivas categorias, verifica-se que nos períodos Transição 2 e chuvoso o estado trófico se mantem em Mesotrófico. Já para os períodos Transição 1 e Seco há melhoria do estado trófico passando de Mesotrófico 
para Oligotrófico. Esse resultado evidencia baixo lançamento de efluente poluidor nos cursos d'água da bacia, pois justamente no período seco quando a vazão diminui, a qualidade da água melhora. Em caso contrário, se o lançamento de efluente fosse significativo haveria concentração de carga poluidora que seria refletida pela piora do IETP. Por outro lado, também se observa aumento da concentração de Fósforo no período chuvoso, impacto direto no potencial de eutrofização, o que pode ser explicado pelo carreamento desse nutriente das lavouras através do escoamento superficial na época chuvosa.

Avaliando os períodos Transição 2 e chuvoso observa tendência de agravamento do potencial de eutrofização pelo fósforo, o que reflete o carreamento de material orgânico particulado da superfície do solo para os cursos d'água que é uma característica natural, embora possa ser potencializada pela má gestão do território agrícola com práticas de conservação de solo inadequadas ou ausentes. Porém, cabe destaque para o fato de que a região é típica de atividades agropecuárias e neste sentido, o carreamento de solo adubado e excrementos de animais podem ser a principal causa do o aporte de Fósforo aos mananciais.

\section{CONCLUSÕES}

A concentração de Fósforo total atende ao VPM da Resolução 357/2005-CONAMA na maioria dos pontos amostrados, indicando boa qualidade da água em relação a essa variável. Os valores de IETp na bacia estudada apresentou diversidade de categorias tróficas, tanto espacial quanto sazonal, revelando águas de muito baixo até intermediário nível trófico. No rio Paraguai a água melhora a sua qualidade trófica entre as proximidades da nascente até a foz do rio Diamantino indicando redução da carga poluidora ao longo do trecho avaliado ou aumento do efeito diluitório combinado com a autodepuração.

O IETp mostrou-se como uma ferramenta eficiente para avaliar a qualidade da água na bacia Paraguai/Diamantino e devido ao seu menor custo de análise pode ser empregado para avaliação da qualidade da água com uma maior frequência de amostragem, o que pode contribuir para a gestão dos recursos hídricos dessa bacia. O IETP é uma tentativa de classificar a qualidade da água de um manancial ou bacia de modo simplificado com base na concentração de fósforo e para uma compreensão mais detalhada da situação geoambiental se faz necessário o uso de outras ferramentas e variáveis, ficando como sugestão para outros estudos futuros.

\section{REFERÊNCIAS}

ABREU, C. H. M.; CUNHA, A. C.. Qualidade da água e índice trófico em rio de ecossistema tropical sob impacto ambiental. Engenharia Sanitária e Ambiental, Rio de Janeiro, v.22, n.1, p.45-56, 2017. DOI: http://dx.doi.org/10.1590/s1413-41522016144803

ALEMAYEHU, D.; HACKETT, F.. Water Quality and Trophic State of Kaw Lake. Journal of Environmental Studies, Oklahoma, v.2, n.1, p.1-7, 2016.

ALVES, I. C. C.; EL-ROBRINI, M.; SANTOS, M. L. S.; MONTEIRO, S. M.; BARBOSA, L. P. F.; GUIMARÃES, J. T. F.. Qualidade das águas superficiais e avaliação do estado trófico do Rio Arari (Ilha de Marajó, norte do Brasil). Acta Amazônica, v.42, n.1, p.115-124, 2012. DOI: http://dx.doi.org/10.1590/S0044$\underline{59672012000100014}$

APHA; AWWA; WEF. American Public Health Association; American Water Works Association; Water Environment Federation. Standard for the Examination of Water and Wastewater. 22 ed. Washington: APHA, 1996.

BAUMGARTEN, M. G. Z.; PAIXÃO, B. E. G.. Uso do índice do estado trófico para avaliar a qualidade das águas do estuário da lagoa dos Patos (RS). Atlântica, Rio Grande, v.35, n.1., p.5-22, 2013. DOI: http://dx.doi.org/10.5088/atl.2013.35.1.5

BRASIL. Portal Nacional de Avaliação da Qualidade das 
Águas. Indicadores de qualidade-Índice de Estado Trófico. Brasília, 2017

CARLSON, R. E.. A trophic state index for lakes. Limnology and Oceanography, Minneapolis, v.22, n.2, p.361-369, 1977

CASARIN, R.. Caracterização dos principais vetores de degradação ambiental da bacia hidrográfica

Paraguai/Diamantino. Tese (Doutorado em Geociências) Universidade Federal do Rio de Janeiro, 2007.

CHAPMAN, D.. Water quality assessment. A guide to the use of biota, sediments and water in environmental monitoring. UNESCO, 1992

CONAMA. Conselho Nacional do Meio Ambiente. Resolução CONAMA, n. 357, de 17 de março de 2005. Brasília: CONAMA, 2005.

FARAGE, J. A. P.; MATOS, A. T.; SILVA, D. D.; BORGES, A. C.. Determinação do índice de estado trófico para fósforo em pontos do rio Pomba. Engenharia na Agricultura, Viçosa, v.18, n.4, p.322-329, 2010.

FERREIRA, P. M. L.; QUEIROZ, M. M. F.; COSTA, F. F.; MEDEIROS, M. C.; GARRIDO, F. W. A.. Determinação do Índice De Estado Trófico para fósforo das águas do Rio Piancó Piranhas Açu no Município de Pombal/PB. Revista Verde de Agroecologia e Desenvolvimento Sustentável, Pombal, v.9, n.4, p.95-101, 2014.

GOMES, D. P. P.; BARROS, F. M.; BARRETO, L. V.; ROSA, R. C. C.; TAGLIAFERRI, C.. Avaliação do estado trófico para o rio Catolé/BA em diferentes épocas do ano. Enciclopédia Biosfera, Centro Científico Conhecer, Goiânia, v.6, n.11, p.16, 2010.

LAMPARELLI, M. C.. Graus de trofia em corpos d'água do estado de São Paulo: avaliação dos métodos de monitoramento. Tese (Doutorado em Ecologia Aplicada) Universidade de São Paulo-Instituto de Biociências, 2004. DOI: http://dx.doi.org/10.11606/T.41.2004.tde-20032006$\underline{075813}$

LOPES, F. W. A.; GUIMARÃES JR., A. P.. Influência das condições naturais de $\mathrm{Ph}$ sobre o índice de qualidade das águas (IQA) na bacia do Ribeirão de Carrancas. Revista Brasileira de Recursos Hídricos, Belo Horizonte, v.6, n.2, p.134-147, 2010

MARTINS, J. A.; DALLACORT, R.; INOUE, M. H.; GALVANIN, E. A. S.; MAGNANI, E. B. Z.; OLIVEIRA, K. C.. Caracterização do regime pluviométrico no arco das nascentes do Rio Paraguai. Revista Brasileira de Meteorologia, v.26, n.4, p.639-647, 2011.

PRASAD, A. G. D.; SIDDARAJU. Carlson's Trophic State Index for the assessment of trophic status of two Lakes in Mandya district. Pelagia Research Library, v.3, n.5, p.2992-2996.

SILVA, G. S.; SANTOS, E. A.; CORRÊA, L. B.; MARQUES, A. L. B.; MARQUES, E. P.; SOUSA, E. R.; SILVA, G. S.. Avaliação integrada da qualidade de águas superficiais: grau de trofia e proteção da vida aquática nos rios Anil e Bacanga, São Luís (MA). Engenharia Sanitária e Ambiental, Rio de Janeiro, v.19, n.3, p.245-250, 2014. DOI: http://dx.doi.org/10.1590/S1413-41522014019000000438

SILVINO, R. F.; BARBOSA, F. A. R.. Eutrophication potential of lakes: an integrated analysis of trophic state, morphometry, land occupation, and land use. Brazilian Journal of Biology, São Carlos, v.75, n.3, p.607-615, 2015. DOI: http://dx.doi.org/10.1590/1519-6984.18913

SOUZA, A. P.; MOTA, L. L.; ZAMADEI, T.; MARTIN, C. C.; ALMEIDA, F. T.; PAULINO, J.. Classificação climática e balanço hídrico climatológico no estado de Mato Grosso. Nativa, Sinop, v.1, n.1, p.34-43, 2013.

A CBPC - Companhia Brasileira de Produção Científica (CNPJ: 11.221.422/0001-03) detém os direitos materiais desta publicação. Os direitos referem-se à publicação do trabalho em qualquer parte do mundo, incluindo os direitos às renovações, expansões e disseminações da contribuição, bem como outros direitos subsidiários. Todos os trabalhos publicados eletronicamente poderão posteriormente ser publicados em coletâneas impressas sob coordenação da Sustenere Publishing, da Companhia Brasileira de Produção Científica e seus parceiros autorizados. Os (as) autores (as) preservam os direitos autorais, mas não têm permissão para a publicação da contribuição em outro meio, impresso ou digital, em português ou em tradução. 